\title{
A Review of P2P Financial Research
}

Shen Hongmei

Shandong DongChang College of LiaoCheng University 252000

Abstract: Since 2007, people's spending habits began to change: from cash to the bank card, from mobile phone to non-cash transactions, from traditional finance to network finance. And the rapid rise of emerging industries results in many of the P2P Financial Corporation established, it makes the P2P platform trading volume continue to rise at an alarming rate. In this context, the industry self-discipline environment is like the mining of good and evil. The atmosphere was foul, bad phenomenon, investors difficult activist phenomenon, the phenomenon of credit default as one falls, another rises to a series of problems, such as serious absence of P2P financial supervision to promote the healthy and sustainable development, is a major problem for all participants, which must to be solved.

Firstly, P2P development of management mode in the current situation in our country is discussed, and then it analyzes the P2P network of financial management platform, finally it proposes the existing problems in the relative countermeasures and suggestions of effective P2P financing mode, hoping to promote its advantages, overcoming the disadvantages of P2P.

Keywords: P2P, network economy model, information mechanism, traditional finance

Published Date: January 2018

Published Online: $31^{\text {st }}$ January 2018

Corresponding Author: Shen Hongmei, The Department of Economic Management Liaocheng University Dongchang College, Head of the Teaching and Research Section, No. 105, the Yellow River Road, Liaocheng Development Zone, Shandong, China,

shenhm04@163.com

\section{Introduction}

In 2005 the first global P2P financial platform was invented in UK, since then, Internet banking is booming rapidly around the world. China's first P2P financial model platform, ppdai.com came out in 2007. After that,a large number of domestic P2P financial platform have emerged. However, China's current laws and regulations on P2P financial control are not standardized, and the basic situation of their business and management is in a vacuum state of supervision. ${ }^{[1-3]}$ In 2016 on the introduction of P2P regulatory rules, it mentioned warning notice about credit risk, inform the possible risks of P2P financing to the public, but also put forward the Interim Measures for the administration of the masses and to solicit public opinions. This also strongly demonstrates that the risk of P2P financial management needs to be controlled. So, what is the development trend of P2P financial management mode in our country at the present stage? What are the problems? One of the factors, because the business model is relatively more lax regulation and low threshold, the crazy growth in recent years, the rapid transmission of information network, P2P financing platform for rapidly expanding its business scope and impact on society; the other factors, the new financial management mode is still in regulatory vacuum, urgent needs to all kinds of problems and legal definition, to guide the development of the health of the new financial management mode.

How can these problems be improved? This paper first analyzes the current development of P2P financing model in our country, and then analyzes its existing problems, and puts forward suggestions to improve the P2P financial management model, hoping to help P2P development.

\section{The development of P2P financing model in China} [5]

Small and micro loans are facing many problems in the developing stage of China, financing many difficulties, from Small and micro businesses and 
individuals to the emergence of this new financial platform. In 2015, the financing platform in terms of the number of institutions or business, this new financial model has been basically formed. It is no exaggeration to say that 2015 was the year of China's network financing. According to the forecast China P2P lending market trends report "data show that 2016-2018 released Analysys enfodesk", especially in 2016, China in P2P network lending market transactions in 2015 compared to a three hundred and thirty-one point six percent increase in size ${ }^{[6]}$, and thus subject to regulatory rulemaking and regulatory agencies at all levels to access restrictions on the P2P lending platform, is expected in 2017 China the P2P network lending market transactions rose to slow turnover will reach 4 trillion yuan.

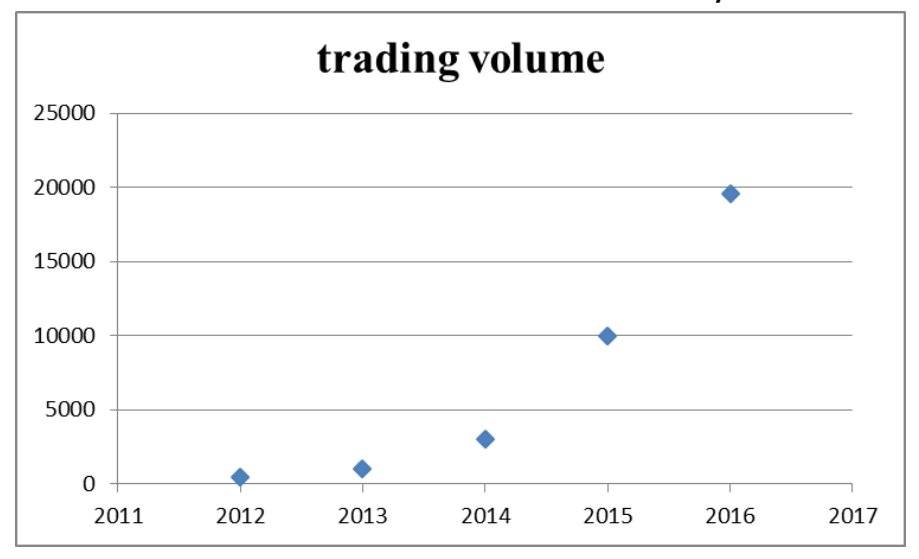

\section{P2P financial problems}

\subsection{Lack of relevant laws and regulations, thus lack of supervision}

What legal issues do we need to pay attention to in the P2P financial management? There are five places need to understand: (1) lending agreement, usually borrow money to sign a loan contract, the contract stipulated in the loan interest period after the occurrence of overdue overdue interest rate and default payment (2) interest rate rules: loan interest rates usually less than twenty-four percent, if more than thirty-six percent of the part without legal protection. (3): first evidence of the validity of contract is the most effective contract but not a top online electronic contract is a contract, need to be added to the electronic signature and timestamp, the court wil accept it (4) judicial proceedings and default bond buying: occurred in the number of $\mathrm{P} 2 \mathrm{P}$ in the default may be very much the cost is too high and the distribution in all parts of the country, can be made by a third party company from lenders to buy claims by third parties as the plaintiff to recover (5) on Security: in lending will usually require collateral, the lender must invest to see if there is no credit guarantee and the guarantor.

\subsection{Lack of funds supervision}

In the operation of the platform, the daily inflow and outflow of funds, the total amount of funds left in the account, the amount of funds in this part is relatively stable. It's like the sediment in a river. Some are washed away and others remain in the bottom of the river. However, the use and ownership of the funds in this part are not related to the laws and regulations. If a platform, the average day precipitation funds at around six million yuan, and for this part of the funds, can only rely on corporate self-regulation, not to transfer this part of the funds.

\subsection{Borrower's credit risk}

Credit risk is also called default risk. In the process of the transaction participants have different information about the relevant information, grasp the personnel information more fully to carry on the correct judgment and information poor personnel are likely to make the wrong decision, but also the asymmetric information leads to adverse selection. The third party platform provides less information about borrowers and fails to fully understand the borrower's overall situation. And this asymmetry of information, resulting in P2P financial markets, the interests of both sides of the transaction imbalances, affecting social fairness and justice, as well as the efficiency of market allocation of resources ${ }^{[7-8]}$. Lenders do not receive information about lenders, and do not understand their repayment, liabilities, ability to repay, family background, and so on, which greatly increase the risk level. At the same time, the third party platform and did not get the support of relevant departments, is usually evaluated in combination with several individuals or institutions to conduct credit, which greatly affected the network lending platform for accurate assessment of 
the borrower's credit situation. Compared with traditional private lending and bank loans, the information asymmetry of online lending is more serious

\section{Improve the P2P financial management of relevant countermeasures}

\subsection{Strengthen personal credit website audit system construction}

Now most of the P2P financial platform of China's credit audit mechanism is not perfect, the personal platform audit mechanism is generally based on the audit mechanism of commercial banks as a template to build, not with the characteristics of the lack of its own characteristics. In the establishment of credit evaluation mechanism with P2P characteristics, we can start from the following aspects: first, the support of the relevant departments. P2P network platform has the characteristics of high speed and convenience, and the speed of information transmission is fast. But because there is no agreement with relevant departments, the risk can not be effectively controlled. Each platform can be evaluated more effectively, truly and comprehensively by means of information sharing and various aspects of the borrower's credit status. Because the borrower's credit situation and the number of loans on other platforms are important indicators to assess whether their credit standing is good. If the platform can effectively work closely with relevant departments, such as banks and public security departments, effective information sources and archival support will be provided to achieve effective control.

Second, we will build a large data repository with each platform of the same industry. Each platform will be uploaded to the database by credit free customers. Strengthen the interaction of each platform information, increase the amount of information on their own platform, but also provide reference for other platforms ${ }^{[9]}$.

Third, the establishment of "Chaoyang masses" system. To encourage bad faith, malicious fraud, overdue returns, to improve the participation in which the enthusiasm. Let everyone maintain stable development in the industry and give a powerful blow to criminals

\subsection{Improve the risk assessment management mechanism}

When the transaction has bad debts or fails to return the principal and interest on the specified date, the platform shall introduce the relevant payment mechanism to protect the rights and interests of the lender. At the moment, a platform uses a conditional principal guarantee system: when the lender meets the required requirements, the borrower is unable to return the debt to the platform on time, i.e., the lender. The introduction of appropriate payment mechanism can effectively protect the rights and interests of lenders, while allowing lenders to believe more platform, so that the platform more credibility, so that more people are willing to understand, participate in the platform transaction. At the same time, the platform is updated every year to ensure that there is no malicious exploit. For example, from 2013 to 2014 the payment mechanism was: first, the lender successfully loaned less than five thousand of each fund, while meeting less than $1 / 3$ of the total amount of the list. Second, when the amount of bad debt is greater than the amount of proceeds, the balance of payment is payable to the lender within three working days of the platform. Money lender investment in accordance with the principal payment mechanism, the platform will ensure the absolute safety of the lender loan principal, if there is bad debt amount is greater than the amount of income, the platform will compensate all losses by people to pay.

In view of the present situation, the lack of credit mechanism, and the network itself, fraud to create a good environment for some criminals, information to identify effectively the difficulty also increases, so to improve the credit management mechanism is particularly important. ${ }^{[10]}$ Some specialized agencies can conduct effective cooperation, formulate a unified credit rating approach, and uniformly assess the borrower's credit rating. ${ }^{[10]}$ At the same time, to deal with the problem of asymmetric information, we can set up information sharing archives to realize 
the information sharing of borrowers and reduce the risk of borrowing. In the establishment of other mechanisms at the same time, but also to the good credit borrowers to a certain degree of reward to encourage, and conversely, for the violation of the provisions of the borrower to economic punishment and the information publicity punishment. After being well known and recognized by the broad masses of the people, the credit mechanism has been developed and perfected, and the network credit has been incorporated into the bank credit as part of the credit reference, so that it can actively promote a better and faster development of the mechanism.

\subsection{Training user strategies}

In addition to the public welfare enterprises, attracting customers and grading customers are the key tasks of management, which is also applicable here.

For the user's training strategy: first, increase the number of customers; second is in the platform for behavior management.

According to the above expression, P2P finance is mainly faced with small capital needs and a small number of idle funds groups. It is not difficult to find a large number of potential customers on the network credit platform. How can a potential customer be transformed into a platform's real customer? This requires platforms to build mechanisms to attract customers. A platform has established a system of principal and interest payment mechanism, which allows investors to trust the platform and attract more customers to invest. At the same time, the platform will also improve the ability to predict risks, reduce the occurrence of bad debts, let the platform get more people's recognition, become the benchmark of the industry, attract more customers.

In other places, such as online credit platforms, there are some customers who do not follow the rules of the game and exploit the system's vulnerabilities. Some people through empty handed "White Wolf" method, with low interest rates on the platform for loans, and then transfer to other people at a high interest rate, this behavior of the network platform's normal operation and development caused an indelible damage. In strengthening supervision but also for overdue or with money Sitao customers to strengthen the crackdown never loan and aggressively pursuing, giving customers a credit trust network platform can be assured.

\section{Summary}

P2P network financial booming in the country in recent years, in a stage of rapid development, is facing a variety of internal and external challenges. These challenges include: 1 . network financing platform as a new thing, the lack of relevant laws and regulations, the lack of effective supervision. 2., the operation of the platform will be precipitated funds, this part of the funds lack of formal supervision and effective use of the Department to curb its size expansion. 3., the lender's investment risk has its own operational risks and bad debts of the two double risks. 4., the industry access threshold is low and the information mechanism is imperfect, a large number of fraud and platform credit risk and personal credit risk parallel. 5., the platform lacks network security protection, once suffered from cyber criminals attacks. The personal information of a large number of users will be disclosed, or even the funds will be hijacked. This requires a correct understanding and effective avoidance of these risks, so as to ensure the sustained and stable development of the network finance industry.

\section{References}

[1] Ma Yunquan, P2P. Development of Internet banking, risk and behavior correction, [J], new finance,.2012 (2), 46-49.

[2] Mo Yixian, P2P network of financial research at home and abroad, the theory and literature review [J] practice, financial theory and practice, 2011 (12): 101-104.

[3] Wang Yan, Chen Xiaohui, Xing Zeng, regulatory gaps in network finance and improvement [J], contemporary economics, 2009 (24), 46-47.

[4] Chen Chen, the thinking of China's "P2P" network 
financing, [J], people's forum,.2010 (26), 128-129.

[5] Chen Jingjun, P2P. Network financing: Problems and Countermeasures in financial innovation [J], science and technology information, 2011 (13), 812765.

[6] Zhang Yumei, P2P. Research on the mode of microfinance [J] productivity research, 2010 (12): 162-165.

[7] Li Guangming, Zhu Zhong, Zhou huan. Empirical Study on the characteristics of borrowers' Arrears in P2P network financing [J], business age, 2011 (1): 41-
42:58.

[8] Shen, loan disintermediation test [J]. new century weekly, 2011, (33): 80-87.

[9] Wang Zi shock, Yuan Zhonghua, Zhong Xin, Chinese P2P network microfinance operation mode - Based on the "pat loans, should agricultural credit analysis of the case of [J], the new finance, 2012 (2), 42-45.

[10] Lu Xin, Li Huimin.Operation Mode and Risk Control of P2P N Network Lending[J].reform,2015(2),60-68. 